\title{
Patterns Associated with Adult Mandibular Fractures in Southern Taiwan-A Cross-Sectional Retrospective Study
}

\author{
Ko-Chien Lin ${ }^{1}$, Shu-Hui Peng ${ }^{1}$, Pao-Jen Kuo ${ }^{1}$, Yi-Chun Chen ${ }^{1}$, Cheng-Shyuan Rau ${ }^{2}$ and \\ Ching-Hua Hsieh ${ }^{1, *}$ \\ 1 Department of Plastic and Reconstructive Surgery, Kaohsiung Chang Gung Memorial Hospital and Chang \\ Gung University College of Medicine, Ta-Pei Road, Niao-Song District, Kaohsiung City 833, Taiwan; \\ kochienlin@gmail.com (K.-C.L.); pshui@cgmh.org.tw (S.-H.P.); bow110470@gmail.com (P.-J.K.); \\ libe320@yahoo.com.tw (Y.-C.C.) \\ 2 Department of Neurosurgery, Kaohsiung Chang Gung Memorial Hospital and Chang Gung University \\ College of Medicine, Ta-Pei Road, Niao-Song District, Kaohsiung City 833, Taiwan; \\ ersh2127@cloud.cgmh.org.tw \\ * Correspondence: m93chinghua@gmail.com; Tel.: +886-7-7327476
}

Academic Editor: David C. Schwebel

Received: 15 June 2017; Accepted: 19 July 2017; Published: 24 July 2017

\begin{abstract}
Purpose: This study aimed to determine the patterns associated with adult mandibular fractures from a Level-I trauma center in southern Taiwan. Methods: The data of adult trauma patients admitted between 1 January 2009 and 31 December 2014 were retrieved from the Trauma Registry System and retrospectively reviewed. Fracture site and cause of injury were categorized into groups for comparison, and corresponding odds ratios (ORs) and 95\% confidence intervals (CIs) were obtained by multivariate logistic regression. Results: Motorcycle accidents were the most common cause of mandibular fractures $(76.3 \%)$, followed by falls $(10.9 \%)$, motor vehicle accidents $(4.8 \%)$, and being struck by/against objects (4.5\%). Of the 503 cases of mandibular fractures, the condylar neck and head were the most common sites (32.0\%), followed by the parasymphysis $(21.7 \%)$, symphysis $(19.5 \%)$, angle and ramus $(17.5 \%)$, and body $(9.3 \%)$. The location of mandibular fractures in patients who had motorcycle accidents was similar to that in all patients. Motor vehicle accidents resulted in a significantly higher number of body fractures (OR 3.3, 95\% CI 1.24-8.76, $p=0.017$ ) and struck injury in a significantly higher number of angle and ramus fractures (OR 3.9, 95\% CI 1.48-10.26, $p=0.006)$ compared to motorcycle accidents. The helmet-wearing status and body weight were not associated with the location of mandibular fractures in motorcycle accidents. Conclusions: Our study revealed that the anatomic fracture sites of mandible were specifically related to different etiologies. In southern Taiwan, motorcycle accidents accounted for the major cause of mandibular fractures and were associated with the condylar neck and head as the most frequent fracture sites. In contrast, motor vehicle accidents and struck injuries tended to cause more body fracture as well as angle and ramus fracture compared to motorcycle accidents. Furthermore, the status of helmet-wearing and body weight were not associated with the location of mandible fractures caused by motorcycle accidents.
\end{abstract}

Keywords: trauma; mandibular fracture; motorcycle accident; helmet

\section{Background}

Mandibular fracture is one of the most common trauma injuries [1]. In Taiwan, among 6013 patients of a 15-year retrospective study, the mandibles were the second most commonly fracture sites $(24.7 \%)$, followed by the nasal bones (22.8\%), but less than the malar and maxillary bones (48.0\%) [2]. A review of the literature indicates that the most common causes of a mandibular fracture are interpersonal 
conflicts or motor vehicle collisions [3-5]. In contrast, in an evaluation of epidemiological data from two European centers, fractures resulted mainly because of assaults and falls [6]. Notably, various fracture sites of the mandible are indicated in different studies [6-8]. Christopher et al. reported that the leading anatomic fractures were most commonly located at the angle $(27 \%)$, followed by the symphysis (21.3\%), condyle and subcondyle (18.4\%), and body (16.8\%) [8]. Fridrich et al. described that the mandibular angle $(28.5 \%)$ is the most common site of fractures, followed by the mandibular symphysis (21.4\%) [4], while King el al. described that parasymphyseal fractures were the most frequent, followed by condyle/head, body, and angle fractures [5]. Obviously, a strong relationship exists between the cause of trauma and anatomic sites of mandibular fractures [4,8,9]. In an analysis of 4143 mandibular fractures, the mandibular angle was the most common fracture site $(31.5 \%)$ in low-velocity blunt injuries (interpersonal conflict, falls, sports-related injury, and struck by falling object), while high-velocity blunt injuries (motor vehicle collisions, motorcycle collisions, and collisions between a motor vehicle and a pedestrian) resulted in a larger number of condylar fractures $(25.4 \%)$, followed by symphysis fractures (22.8\%) [8]. Zhou et al. reported that falls at a ground level and from a height were associated with a 9.64-fold and 9.17-fold risk of mandibular condylar fractures, respectively, while no significant relationship existed between assault and condylar fractures [9]. Bolagi et al. found that the increasing trend of interpersonal violence caused a shift in the location of mandible fractures from symphyseal-condylar complex to angle-body/parasymphyseal complex [10].

In Taiwan, traveling by motorcycle has been a common part of daily life and remains a crucial mode of transportation [11,12], and as a result, motorcyclists comprise a major portion of the trauma population [13-15]. Therefore, the cause and location of mandibular fractures in Taiwan may differ from that observed in Western countries and should be re-evaluated, especially considering that almost all motorcycles are forbidden on highways in Taiwan and most motorcycle traffic accidents occur in relatively crowded streets and at low velocities $[13,16,17]$. Under the hypothesis that the anatomic fracture sites of mandible are specifically related to different trauma mechanisms, this study examined patients with mandibular fractures in Taiwan with a specific focus on motorcycle accidents as a cause and provides an epidemiological picture from a Level-I trauma center in southern Taiwan.

\section{Methods}

The study was conducted at Kaohsiung Chang Gung Memorial Hospital, a 2400-bed facility and Level-I trauma center that provides care to trauma patients, primarily from the southern region of Taiwan. This study was approved by the institutional review board (IRB) of Kaohsiung Chang Gung Memorial Hospital with approval number 105-1108C. Informed consent was waived according to IRB regulations. A retrospective study was designed to review all data of patients who were entered into the Trauma Registry System between 1 January 2009 and 31 December 2014. The inclusion criteria were as follows: (1) age $\geq 20$ years, (2) patients suffering from mandibular fracture. Patients with incomplete registered data were excluded from this study. Detailed patient information was retrieved from the Trauma Registry System of our institution and included data regarding age, sex, cause of injury (motorcycle accident, fall accident, motor vehicle accident, struck by/against objects, bicycle accident, and pedestrian injury in a traffic accident), helmet use, the first Glasgow Coma Scale (GCS) during admission in the emergency department, the GCS and associated head injury. Underweight patients were defined as a body mass index (BMI) of $<18.5 \mathrm{~kg} / \mathrm{m}^{2}$ and normal-weight patients with a BMI of $<25$ but $\geq 18.5 \mathrm{~kg} / \mathrm{m}^{2}$, overweight patients with a BMI $\geq 25 \mathrm{but}<30 \mathrm{~kg} / \mathrm{m}^{2}$, and obese patients with a BMI $\geq 30 \mathrm{~kg} / \mathrm{m}^{2}$. Multivariate logistic regression were used to compare the category variables and corresponding odds ratios (ORs) and $95 \%$ confidence intervals (CIs) were obtained, taking the cause of motorcycle accidents as the reference category. In motorcycle accident, sex, age, helmet-wearing status, and BMI categories were chosen as covariates in multivariate analyses to evaluate the association of helmet-wearing status or BMI categories with the fracture pattern of mandibular fracture. All results are presented as the mean \pm standard deviation. A $p$-value less than 0.05 was considered statistically significant. 


\section{Results}

From 1 January 2009 to 31 December 2014, the Trauma Registry System included 20,106 hospitalized and registered patients. There were 396 patients that had sustained a mandibular fracture. After excluding 83 patients who aged less than 20 years and one patient who had incomplete data, a total of 503 mandibular fractures suffered by 312 patients were included (Table 1). Of these patients, 207 were men and 105 were women, resulting in a ratio of 2:1. The mean age was $36.5 \pm 15.2$ years. Motorcycle accident accounted for the major cause of mandibular fracture (76.3\%), followed by fall (10.9\%), motor vehicle accident (4.8\%), and struck by/against objects (4.5\%). Bicycle accident and pedestrian injury in a traffic accident only represented $2.2 \%$ and $1.3 \%$, respectively, of the cause of injury. These patients with mandibular fractures presented with a GCS of $13.5 \pm 3.1$ upon arrival at the emergency department, with $11.2 \%$ of patients being in a severe comatose condition (GCS $\leq 8)$. Of the patients with mandibular fractures, $11.5 \%$ had cranial fracture, $5.8 \%$ had epidural hematoma, $10.3 \%$ had subdural hematoma, $10.9 \%$ had subarachnoid hemorrhage, $2.6 \%$ had intracerebral hematoma, and 4.5\% had a cerebral contusion, resulting in 107 of 312 (34.3\%) patients suffering a severe head injury, such as cranial fracture or traumatic brain injury. Of the 503 fracture sites of the mandible, condylar neck and head comprised the most common parts of mandibular fractures $(32.0 \%)$, followed by parasymphysis $(21.7 \%)$, symphysis $(19.5 \%)$, angle and ramus $(17.5 \%)$, and body $(9.3 \%)$.

Table 1. Demographics and injury characteristics of adult trauma patients with mandible fractures.

\begin{tabular}{lc}
\hline Variables & Patients $N=\mathbf{3 1 2}$ \\
\hline Gender (\%) & \\
\hline Male & $207(66.3)$ \\
Female & $105(33.7)$ \\
\hline Age & $36.5 \pm 15.2$ \\
\hline Cause (\%) & \\
\hline Motorcycle accident & $238(76.3)$ \\
Fall & $34(10.9)$ \\
Motor vehicle accident (MVA) & $15(4.8)$ \\
Struck by/against objects & $14(4.5)$ \\
Bicycle accident & $7(2.2)$ \\
Pedestrian & $4(1.3)$ \\
\hline GCS & $13.5 \pm 3.1$ \\
\hline$\leq 8$ (\%) & $35(11.2)$ \\
9-12 (\%) & $23(7.4)$ \\
$\geq 13$ (\%) & $254(81.4)$ \\
\hline Associated head injury (\%) & \\
\hline Cranial fracture & $36(11.5)$ \\
Epidural hematoma (EDH) & $18(5.8)$ \\
Subdural hematoma (SDH) & $32(10.3)$ \\
Subarachnoid hemorrhage (SAH) & $34(10.9)$ \\
Intracerebral hematoma (ICH) & $8(2.6)$ \\
Cerebral contusion & $14(4.5)$ \\
Cervical vertebral fracture & $4(1.3)$ \\
\hline Site of mandibular fracture (\%) & $n=503$ \\
\hline Symphysis & $98(19.5)$ \\
Parasymphysis & $109(21.7)$ \\
Body & $47(9.3)$ \\
Angle and Ramus & $88(17.5)$ \\
Condylar neck and Head & $161(32.0)$ \\
\hline \multicolumn{1}{c}{$N=$ number of patients, $n=$ number of fractures. } \\
\hline
\end{tabular}


As shown in the Figure 1 and Table 2, the location of mandibular fractures in motorcycle accident patients presented a profile similar to the one for all patients, as condylar neck and head comprised the most common parts of mandibular fractures $(33.0 \%)$, followed by parasymphysis $(22.4 \%)$, symphysis $(19.6 \%)$, angle and ramus (17.0), and body (8.0\%). Compared to motorcycle accidents, motor vehicle accidents resulted in a significant increase in body fractures (OR 3.3, 95\% CI 1.24-8.76, $p=0.017$ ) and struck injury caused a significant higher number of angle and ramus fractures (OR 3.9, 95\% CI $1.48-10.26, p=0.006$ ), but less condylar neck and head fractures (OR 0.1, 95\% CI 0.02-0.91, $p=0.040$ ). Patients suffering from fractures caused by fall accidents, bicycle accidents, or injuries as a pedestrian had no significant difference in location of mandibular fractures in comparison to fractures caused by motorcycle accidents. In addition, the multivariate analyses (Table 3) revealed that the status of helmet-wearing and body weight were not associated with the location of mandible fractures caused by motorcycle accidents.
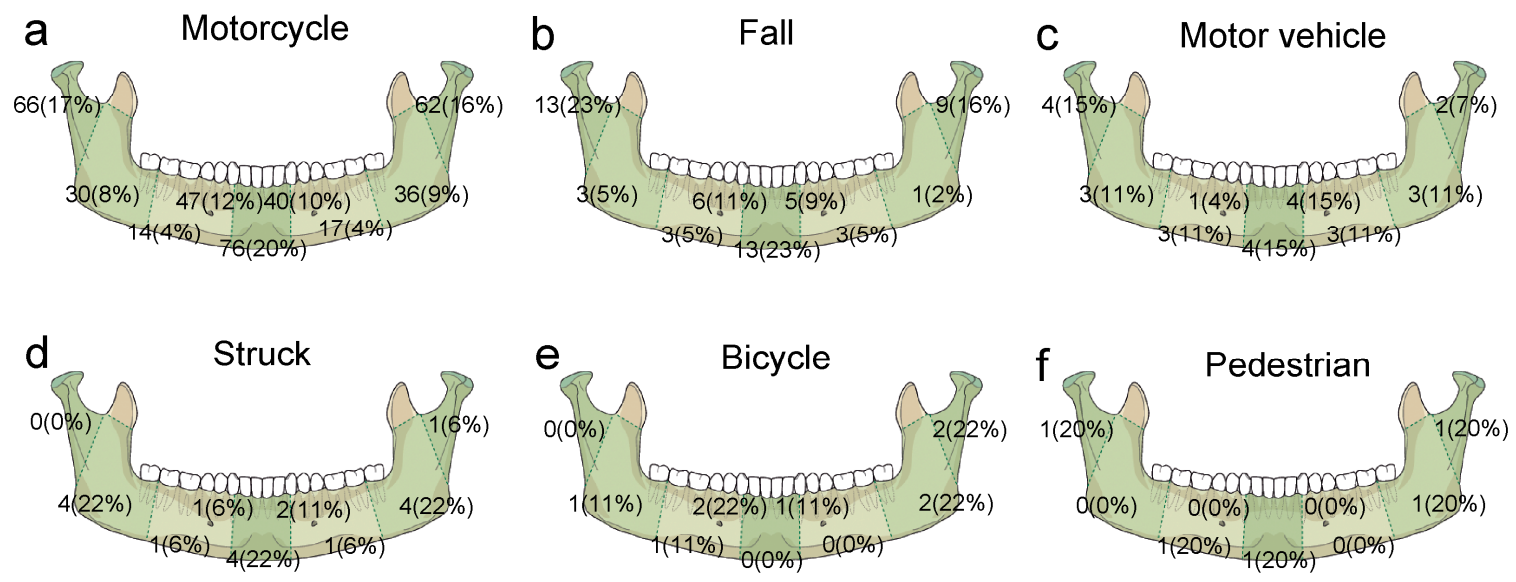

Figure 1. Numbers and percentage of patients per fracture sites of the mandible caused by different trauma. (a) motorcycle; (b) fall; (c) motor vehicle; (d) struck; (e) bicycle; (f) pedestrian. 
Table 2. The association between cause of trauma and sites of mandibular fractures.

\begin{tabular}{|c|c|c|c|c|c|c|c|c|c|c|}
\hline Variables & \multicolumn{2}{|c|}{ Fall $n=56$ (II) } & \multicolumn{2}{|c|}{ MVA $n=27$ (III) } & \multicolumn{2}{|c|}{ Struck by/against $n=18$ (IV) } & \multicolumn{2}{|c|}{ Bicycle $n=9(\mathrm{~V})$} & \multicolumn{2}{|c|}{ Pedestrian $n=5$ (VI) } \\
\hline Symphysis & \multicolumn{2}{|l|}{$13(23.2)$} & \multicolumn{2}{|l|}{$4(14.8)$} & \multicolumn{2}{|c|}{$4(22.2)$} & \multicolumn{2}{|l|}{$0(0.0)$} & \multicolumn{2}{|l|}{$1(20.0)$} \\
\hline Parasymphysis & \multicolumn{2}{|l|}{$11(19.6)$} & \multicolumn{2}{|l|}{$5(18.5)$} & \multicolumn{2}{|c|}{$3(16.7)$} & \multicolumn{2}{|l|}{$3(33.3)$} & \multicolumn{2}{|l|}{$0(0.0)$} \\
\hline Body & \multicolumn{2}{|l|}{$6(10.7)$} & \multicolumn{2}{|l|}{$6(22.2)$} & \multicolumn{2}{|c|}{$2(11.1)$} & \multicolumn{2}{|l|}{ 1(11.1) } & \multicolumn{2}{|c|}{$1(20.0)$} \\
\hline Angle and Ramus & \multicolumn{2}{|l|}{$4(7.1)$} & \multirow{2}{*}{\multicolumn{2}{|c|}{$\begin{array}{l}0(22.2) \\
\end{array}$}} & \multicolumn{2}{|c|}{$8(44.4)$} & \multicolumn{2}{|l|}{$3(33.3)$} & \multicolumn{2}{|c|}{$1(20.0)$} \\
\hline Condylar neck and Head & \multicolumn{2}{|l|}{$22(39.3)$} & & & \multicolumn{2}{|c|}{$1(5.6)$} & $2(22.2)$ & & \multicolumn{2}{|c|}{$2(40.0)$} \\
\hline \multirow{2}{*}{ Variables } & OR $(95 \% C I)$ & $p$ & OR $(95 \% C I)$ & $p$ & OR $(95 \% C I)$ & $p$ & OR $(95 \% C I)$ & $p$ & OR $(95 \% C I)$ & $p$ \\
\hline & \multicolumn{2}{|l|}{ II vs. I } & \multicolumn{2}{|l|}{ III vs. I } & \multicolumn{2}{|c|}{ IV vs. I } & \multicolumn{2}{|l|}{ V vs. I } & \multicolumn{2}{|c|}{ VI vs. I } \\
\hline Symphysis & $1.2(0.64-2.42)$ & 0.527 & $0.7(0.24-2.13)$ & 0.545 & $1.2(0.38-3.66)$ & 0.784 & - & 0.999 & $1.0(0.11-9.34)$ & 0.982 \\
\hline Parasymphysis & $0.8(0.421 .71)$ & 0.639 & $0.8(0.29-2.14)$ & 0.637 & $0.7(0.20-2.45)$ & 0.567 & $1.7(0.42-7.06)$ & 0.445 & - & 0.999 \\
\hline Body & $1.4(0.55-3.48)$ & 0.492 & $3.3(1.24-8.76)$ & 0.017 & $1.4(0.32-6.55)$ & 0.637 & $1.4(0.17-11.89)$ & 0.735 & $2.9(0.31-26.56)$ & 0.351 \\
\hline Angle and Ramus & $0.4(0.13-1.07)$ & 0.068 & $1.4(0.54-3.59)$ & 0.491 & $3.9(1.48-10.26)$ & 0.006 & $2.4(0.60-10.00)$ & 0.215 & $1.2(0.13-11.09)$ & 0.860 \\
\hline
\end{tabular}

Table 3. The association between helmet use and body mass index (BMI) in motorcycle accidents and sites of mandibular fractures.

\begin{tabular}{|c|c|c|c|c|c|c|c|c|c|c|}
\hline Variables & \multicolumn{2}{|c|}{ Symphysis $n=76$} & \multicolumn{2}{|c|}{ Parasymphysis $n=87$} & \multicolumn{2}{|c|}{ Body $n=31$} & \multicolumn{2}{|c|}{ Angle and Ramus $n=66$} & \multicolumn{2}{|c|}{ Condyle and Head $n=128$} \\
\hline Age & \multirow{2}{*}{\multicolumn{2}{|c|}{$\begin{array}{c}32.2 \pm 10.9 \\
29 / 47\end{array}$}} & \multirow{2}{*}{\multicolumn{2}{|c|}{$\begin{array}{c}32.2 \pm 12.2 \\
30 / 57\end{array}$}} & \multirow{2}{*}{\multicolumn{2}{|c|}{$\begin{array}{c}39.0 \pm 16.4 \\
7 / 24\end{array}$}} & \multirow{2}{*}{\multicolumn{2}{|c|}{$\begin{array}{c}35.5 \pm 17.1 \\
24 / 42\end{array}$}} & \multicolumn{2}{|c|}{$33.6 \pm 13.4$} \\
\hline Gender (M/F) & & & & & & & & & $60 /$ & \\
\hline \multicolumn{11}{|l|}{ BMI classification } \\
\hline Obese & \multicolumn{2}{|l|}{$4(5.3)$} & \multicolumn{2}{|l|}{$8(9.2)$} & \multicolumn{2}{|c|}{$0(0.0)$} & \multicolumn{2}{|c|}{$3(4.5)$} & \multicolumn{2}{|c|}{$5(3.9)$} \\
\hline Overweight & \multirow{2}{*}{\multicolumn{2}{|c|}{$16(21.1)$}} & \multirow{2}{*}{\multicolumn{2}{|c|}{$19(21.8)$}} & \multirow{2}{*}{\multicolumn{2}{|c|}{$9(29.0)$}} & \multirow{2}{*}{\multicolumn{2}{|c|}{$14(21.2)$}} & \multirow{2}{*}{\multicolumn{2}{|c|}{$22(17.2)$}} \\
\hline Underweight & & & & & & & \multirow{2}{*}{\multicolumn{2}{|c|}{$\begin{array}{c}3(4.5) \\
43(65 ?)\end{array}$}} & & \\
\hline Normal & \multicolumn{2}{|l|}{$\begin{array}{c}7(9.2) \\
45(59.2)\end{array}$} & \multicolumn{2}{|c|}{$53(60.9)$} & \multicolumn{2}{|c|}{$20(64.5)$} & & & & \\
\hline Unknown & \multicolumn{2}{|l|}{$4(5.3)$} & \multicolumn{2}{|l|}{$2(2.3)$} & \multicolumn{2}{|c|}{$0(0.0)$} & \multicolumn{2}{|c|}{$\begin{array}{l}3(4.5) \\
3(0.5)\end{array}$} & \multicolumn{2}{|c|}{$\begin{array}{c}83(64.8) \\
7(5.5)\end{array}$} \\
\hline \multicolumn{11}{|l|}{ Helmet use } \\
\hline Yes & \multirow{2}{*}{\multicolumn{2}{|c|}{ 58(76.3) }} & $71(81.6$ & & & 3.5) & $50(75$. & & $112(8$ & \\
\hline No & & & $14(16.1$ & & & & $13(19$. & & $14(10$ & \\
\hline Unknown & $5(6.6)$ & & $2(2.3)$ & & & & $3(4.5$ & & $2(1$. & \\
\hline Variables & Symphys & & Parasympl & & & & Angle and & mus & Condyle a & Head \\
\hline validoies & OR $(95 \% C I)$ & $p$ & OR $(95 \%$ CI $)$ & $p$ & OR $(95 \% C I)$ & & OR $(95 \% C I)$ & $p$ & OR $(95 \% C I)$ & $p$ \\
\hline BMI classification & & & & & & BMI classification & & & & \\
\hline Obese & $1.2(0.38-3.91)$ & 0.739 & $1.9(0.72-5.21)$ & 0.192 & - & Obese & $1.2(0.38-3.91)$ & 0.739 & $1.9(0.72-5.21)$ & 0.192 \\
\hline Overweight & $1.3(0.65-2.51)$ & 0.486 & $1.2(0.66-2.31)$ & 0.502 & $1.0(0.41-2.35)$ & Overweight & $1.3(0.65-2.51)$ & 0.486 & $1.2(0.66-2.31)$ & 0.502 \\
\hline Underweight & $1.5(0.56-4.05)$ & 0.418 & $1.0(0.34-2.70)$ & 0.933 & $1.3(0.28-6.38)$ & Underweight & $1.5(0.56-4.05)$ & 0.418 & $1.0(0.34-2.70)$ & 0.933 \\
\hline Helmet use & & & & & & Helmet use & & & & \\
\hline Yes & $0.6(0.29-1.22)$ & 0.158 & $0.9(0.45-1.84)$ & 0.803 & $3.9(0.87-17.26)$ & Yes & $0.6(0.29-1.22)$ & 0.158 & $0.9(0.45-1.84)$ & 0.803 \\
\hline
\end{tabular}




\section{Discussion}

In contrast to studies that indicated that motor vehicle accidents and assaults comprised the majority of causes of mandibular fractures [3-5,9], our study showed that only $9.3 \%$ of mandible fractures were caused by these two actions. Our study revealed that motorcycle accidents accounted for the major cause of mandibular fractures in southern Taiwan. In both the motorcyclist group and the group with all patients, the condylar neck and head were the most frequent location for fractures, followed by the parasymphysis, symphysis, angle and ramus, and body. In addition, motor vehicle accidents caused more body fractures, while struck injuries caused more angle and ramus fractures compared to motorcycle accidents. For motorcycle accidents, the vector of force is often applied on the mandible in anterior-posterior direction, which initiates the force posteriorly to the condyles. The results are in accordance with that reported by Morris et al., who indicated that a high-velocity blunt injury like motorcycle collisions would result in a larger number of condylar fractures, while the mandibular angle is the most common fracture site involved in a low-velocity blunt injury like assault or struck injury [8]. However, in this study, high-velocity blunt injury like motor vehicle accidents showed a 3.3-fold increase in body fractures compared to motorcycle accidents, this observation is not in accordance with the reports from some studies that indicated symphysis and parasymphysis fractures are the most involved anatomic sites $[9,18,19]$. Because of the structure and anatomic proximity of the mandible as well as its direct connection to the skull base, trauma to the mandible is related to intracranial injury, and traumatic brain injuries were observed in $19 \%$ of trauma patients with mandibular fractures [20]. A 75\% (12 of 16) rate of concussions associated with isolated mandible fracture has been reported [21]. Similarly, closed head injury has been identified in $32.4 \%$ of patients with mandible fractures caused by motor vehicle accidents [22]. It was reported that $16.2 \%$ of patients with mandibular fractures fit the indication of neurosurgical treatment [23]. In this study, $34.3 \%$ patients with mandibular fractures suffered from concomitant cranial fractures or traumatic brain injury, and therefore physicians should be aware of this when evaluating patients with mandibular fractures.

The protective effect of motorcycle helmets is already well-established in the literature regarding head injury [24-27] and extensive injury in the face [28]. In a review of 272 helmeted and non-helmeted victims with moderate traumatic brain injury admitted at a referral trauma hospital, the only facial bone fracture with significant association with the type of helmet was the Le Fort fracture [28]. In this study, we did not identify an association of helmet-wearing status and the location of mandible fractures caused by motorcycle accidents. However, the type of helmet (opened helmet or full-face helmet) in the accidents was unknown. In addition, although it has been reported that obese trauma patients experience fewer mandibular fractures than normal bodyweight patients in Taiwan [17,29], we found no significant association between weight of patients and mandibular fracture sites.

Limitations of this study are the retrospective design and the lack of available data regarding conditions including speed, helmet material and design, and prior history of facial bone fracture. Additionally, the number of patients in the study was relatively small, which excluded an in-depth examination of variables, such as the elderly. Furthermore, lack of availability of important confounders regarding the circumstances of the mechanism of injury, exposure data, protection methods, and associated facial bone fractures may result in selection bias. A relatively small population of patients suffered from a bicycle accident or was injured as a pedestrian, making the interpretation or analysis of these groups of patients less meaningful. In addition, patients who had died before arrival at the hospital or at accident scenes were not included in the Trauma Registry Database, thereby creating a selection bias. Finally, this study is limited to one trauma center, thus a selection bias is possible.

\section{Conclusions}

Our study revealed that the anatomic fracture sites of mandible were specifically related to different etiologies. In southern Taiwan, motorcycle accidents accounted for the major cause of mandibular fractures and were associated with the condylar neck and head as the most frequent 
fracture sites. In contrast, motor vehicle accidents and struck injuries tended to cause more body fracture as well as angle and ramus fracture compared to motorcycle accidents. Furthermore, the status of helmet-wearing and body weight were not associated with the location of mandible fractures caused by motorcycle accidents.

Acknowledgments: This research was supported by a grant from CMRPG8F0371.

Author Contributions: Ko-Chien Lin wrote the manuscript, Shu-Hui Peng edited the tables, Pao-Jen Kuo interpreted the data, Yi-Chun Chen performed the statistical analyses, Cheng-Shyuan Rau proofread the manuscript, and Ching-Hua Hsieh designed the study, contributed to the statistical analysis and data interpretation, and revised the manuscript. All authors read and approved the final manuscript.

Conflicts of Interest: The authors declare that they have no competing interests.

\section{References}

1. Czerwinski, M.; Parker, W.; Chehade, A.; Williams, H. Identification of mandibular fracture epidemiology in Canada: Enhancing injury prevention and patient evaluation. Can. J. Plast. Surg. 2008, 16, 36-40. [CrossRef] [PubMed]

2. Yang, C.S.; Chen, S.C.; Yang, Y.C.; Huang, L.C.; Guo, H.R.; Yang, H.Y. Epidemiology and patterns of facial fractures due to road traffic accidents in Taiwan: A 15-year retrospective study. Traffic Inj. Prev. 2017, 3, 1-6. [CrossRef] [PubMed]

3. Olson, R.A.; Fonseca, R.J.; Zeitler, D.L.; Osbon, D.B. Fractures of the mandible: A review of 580 cases. J. Oral Maxillofac. Surg. 1982, 40, 23-28. [CrossRef]

4. Fridrich, K.L.; Pena-Velasco, G.; Olson, R.A. Changing trends with mandibular fractures: A review of 1067 cases. J. Oral Maxillofac. Surg. 1992, 50, 586-589. [CrossRef]

5. King, R.E.; Scianna, J.M.; Petruzzelli, G.J. Mandible fracture patterns: A suburban trauma center experience. Am. J. Otolaryngol. 2004, 25, 301-307. [CrossRef] [PubMed]

6. Boffano, P.; Kommers, S.C.; Karagozoglu, K.H.; Gallesio, C.; Forouzanfar, T. Mandibular trauma: A two-centre study. Int. J. Oral Maxillofac. Surg. 2015, 44, 998-1004. [CrossRef] [PubMed]

7. Lamphier, J.; Ziccardi, V.; Ruvo, A.; Janel, M. Complications of mandibular fractures in an urban teaching center. J. Oral Maxillofac. Surg. 2003, 61, 745-749. [CrossRef]

8. Morris, C.; Bebeau, N.P.; Brockhoff, H.; Tandon, R.; Tiwana, P. Mandibular fractures: An analysis of the epidemiology and patterns of injury in 4143 fractures. J. Oral Maxillofac. Surg. 2015, 73, 951.e1-951.e12. [CrossRef] [PubMed]

9. Zhou, H.H.; Hu, T.Q.; Liu, Q.; Ongodia, D.; Li, Z.B. Does trauma etiology affect the pattern of mandibular fracture? J. Craniofac. Surg. 2012, 23, e494-e497. [CrossRef] [PubMed]

10. Ogundare, B.O.; Bonnick, A.; Bayley, N. Pattern of mandibular fractures in an urban major trauma center. J. Oral Maxillofac. Surg. 2003, 61, 713-718. [CrossRef] [PubMed]

11. Lam, C.; Lin, M.R.; Chu, S.F.; Tsai, S.H.; Bai, C.H.; Chiu, W.T. The effect of various types of motorcycle helmets on cervical spine injury in head injury patients: A multicenter study in Taiwan. BioMed Res. Int. 2015, 2015, 487985. [CrossRef] [PubMed]

12. Chang, H.L.; Lai, C.Y. Using travel socialization and underlying motivations to better understand motorcycle usage in Taiwan. Accid. Anal. Prev. 2015, 79, 212-220. [CrossRef] [PubMed]

13. Liu, H.T.; Liang, C.C.; Rau, C.S.; Hsu, S.Y.; Hsieh, C.H. Alcohol-related hospitalizations of adult motorcycle riders. World J. Emerg. Surg. 2015, 10, 2. [CrossRef] [PubMed]

14. Hsieh, C.H.; Hsu, S.Y.; Hsieh, H.Y.; Chen, Y.C. Differences between the sexes in motorcycle-related injuries and fatalities at a Taiwanese level I trauma center. Biomed. J. 2017, 40, 113-120. [CrossRef] [PubMed]

15. Hsieh, C.H.; Liu, H.T.; Hsu, S.Y.; Hsieh, H.Y.; Chen, Y.C. Motorcycle-related hospitalizations of the elderly. Biomed. J. 2017, 40, 121-128. [CrossRef] [PubMed]

16. Liang, C.C.; Liu, H.T.; Rau, C.S.; Hsu, S.Y.; Hsieh, H.Y.; Hsieh, C.H. Motorcycle-related hospitalization of adolescents in a Level I trauma center in Southern Taiwan: A cross-sectional study. BMC Pediatr. 2015, 15, 105. [CrossRef] [PubMed] 
17. Liu, H.T.; Rau, C.S.; Wu, S.C.; Chen, Y.C.; Hsu, S.Y.; Hsieh, H.Y.; Hsieh, C.H. Obese motorcycle riders have a different injury pattern and longer hospital length of stay than the normal-weight patients. Scand. J. Trauma Resusc. Emerg. Med. 2016, 24, 50. [CrossRef] [PubMed]

18. Pontes, H.A.R.; Pontes, F.S.C.; Lameira, A.G.; Salim, R.A.; de Carvalho, P.L.; Guimarães, D.M.; dos Santos Pinto, D. Report of four cases of ameloblastic fibro-odontoma in mandible and discussion of the literature about the treatment. J. Cranio-Maxillofac. Surg. 2012, 40, e59-e63. [CrossRef] [PubMed]

19. Al Ahmed, H.E.; Jaber, M.A.; Abu Fanas, S.H.; Karas, M. The pattern of maxillofacial fractures in Sharjah, United Arab Emirates: A review of 230 cases. Oral Surg. Oral Med. Oral Pathol. Oral Radiol. Endod. 2004, 98, 166-170. [CrossRef] [PubMed]

20. Czerwinski, M.; Parker, W.L.; Williams, H.B. Algorithm for head computed tomography imaging in patients with mandible fractures. J. Oral Maxillofac. Surg. 2008, 66, 2093-2097. [CrossRef] [PubMed]

21. Sobin, L.; Kopp, R.; Walsh, R.; Kellman, R.M.; Harris, T. Incidence of concussion in patients with isolated mandible fractures. JAMA Facial Plast. Surg. 2016, 18, 15-18. [CrossRef] [PubMed]

22. Fischer, K.; Zhang, F.; Angel, M.F.; Lineaweaver, W.C. Injuries associated with mandible fractures sustained in motor vehicle collisions. Plast. Reconstr. Surg. 2001, 108, 328-331. [CrossRef] [PubMed]

23. Salentijn, E.G.; Peerdeman, S.M.; Boffano, P.; van den Bergh, B.; Forouzanfar, T. A ten-year analysis of the traumatic maxillofacial and brain injury patient in Amsterdam: Incidence and aetiology. J. Cranio-Maxillofac. Surg. 2014, 42, 705-710. [CrossRef] [PubMed]

24. Hooten, K.G.; Murad, G. Helmeted vs. nonhelmeted: A retrospective review of outcomes from 2-wheeled vehicle accidents at a level 1 trauma center. Clin. Neurosurg. 2012, 59, 126-130. [CrossRef] [PubMed]

25. Liu, B.C.; Ivers, R.; Norton, R.; Boufous, S.; Blows, S.; Lo, S.K. Helmets for preventing injury in motorcycle riders. Cochrane Libr. 2008. [CrossRef]

26. Muller, A. Florida's motorcycle helmet law repeal and fatality rates. Am. J. Public Health 2004, 94, 556-558. [CrossRef] [PubMed]

27. Vaca, F. National Highway Traffic Safety Administration (NHTSA) notes. Evaluation of the repeal of the all-rider motorcycle helmet law in Florida. Ann. Emerg. Med. 2006, 47. [CrossRef]

28. Cavalcante, J.R.; Oka, S.C.; de Santana Santos, T.; Dourado, E.; de Oliveira, E.S.E.D.; Gomes, A.C. Influence of helmet use in facial trauma and moderate traumatic brain injury victims of motorcycle accidents. J. Craniofac. Surg. 2012, 23, 982-985. [CrossRef] [PubMed]

29. Chuang, J.F.; Rau, C.S.; Kuo, P.J.; Chen, Y.C.; Hsu, S.Y.; Hsieh, H.Y.; Hsieh, C.H. Traumatic injuries among adult obese patients in Southern Taiwan: A cross-sectional study based on a trauma registry system. BMC Public Health 2016, 16, 275. [CrossRef] [PubMed] 